\title{
Application of the EULAR/ACR 2010 classification criteria in the early diagnosis of RA
}

\author{
Mario A. Garza-Elizondo* and Cesar V. Elizondo-Solís \\ Rheumatology Service, Hospital Universitario “Dr. José Eleuterio González”, Universidad Autónoma de Nuevo León, Monterrey, Nuevo Leon, Mexico
}

\section{What is Rheumatoid Arthritis?}

Rheumatoid arthritis is a systemic, autoimmune, chronic, inflammatory disease, with the synovial membrane being its main target organ. It is characterized by polyarticular and systemic inflammation of small and large joints. Without the proper treatment, it can lead to irreversible articular injury and result in a disabling limitation, affecting the quality of life of whoever presents it.

\section{Who can have RA?}

RA prevalence worldwide is between 0.2 and $2 \%$. In Mexico, it is $1.6 \%$. This condition is more frequent in women than men and occurs between 40 and 60 years of age 1 .

\section{What is the diagnostic approach?}

Today, this EULAR/ACR Criteria 2010 for the Classification of RA is currently in place ${ }^{2}$.

\begin{tabular}{|l|l|c|}
\hline Domain & Category & Score \\
\hline A & Involved joints $^{\text {A }}$ & \\
\hline \multirow{4}{*}{1 large joint } & 0 \\
$2-10$ large joints & 1 \\
& $1-3$ small joints & 2 \\
$4-10$ small joints & 3 \\
& $>10$ joints including at least a small joint & 5 \\
\hline
\end{tabular}

\begin{tabular}{|l|l|l|}
\hline B & $\begin{array}{l}\text { Serology } \\
\text { Negative RF and ACPA } \\
\text { Low-level positive RF or low-level positive }\end{array}$ & 0 \\
\hline $\begin{array}{l}\text { ACPA } \\
\text { High-level positive RF or high-level } \\
\text { positive ACPA }\end{array}$ & 3 \\
\hline & $\begin{array}{l}\text { Acute phase reactants } \\
\text { Normal VSG or normal PCR } \\
\text { Abnormal VSG or abnormal PCR }\end{array}$ & 0 \\
\hline C & 1 \\
\hline Dymptom duration D \\
$\quad<6$ weeks \\
$\quad>6$ weeks & 0 \\
\hline
\end{tabular}

The scores of domains A through $D$ are added, and the result is considered the total score. With a score $>6$, it is necessary to classify the patient with RA. A: articular involvement refers to the presence of pain or joint inflammation during physical examination. Large joints include shoulders, elbows, hips, knees, and ankles. Small joints refer to MCP, PIP, $2^{\text {nd }}$ to $5^{\text {th }}$ MTP, wrist, and thumb IP. B: normal means less than or equal to the normal superior limit (NSL); low level $>\mathrm{NSL}$ and high level >×3 NSL. C: normal and abnormal are determined by lab standards. $D$ : the patient refers to the duration of symptoms.

These criteria allow for the classification of patients with rheumatoid arthritis; however, they are not diagnostics. Its objective is to identify those individuals to be included in clinical essays or other research studies in a standardized way. Diagnosis of rheumatoid arthritis is made based on
Correspondence:

*Mario A. Garza-Elizondo

E-mail: mariogarz@ hotmail.com
Available online: 01-12-2021

Date of reception: 04-08-2021

Date of acceptance: 04-10-2021 DOI: 10.24875/RMU.M21000061

\section{Medicina Universitaria. 2021;23(4):153-154} www.medicinauniversitaria.org

1665-5796/C 2021 Universidad Autónoma de Nuevo León. Published by Permanyer. This is an open access article under the CC BY-NC-ND license (http://creativecommons.org/licenses/by-nc-nd/4.0/). 
clinical manifestations. While the use of laboratory studies and imaging can be beneficial to confirm clinical suspicions and obtain information on the prognosis, they are not indispensable to performing a diagnosis.

Detecting clinical manifestations is the most important point to make an early diagnosis. The patient usually presents a history of pain and inflammation of the lower limbs, mainly the feet and hands, symmetrically and bilaterally for a period of over 6 weeks. It is worth noting that morning rigidity for more than $60 \mathrm{~min}$ is a frequent symptom, as is fatigue.

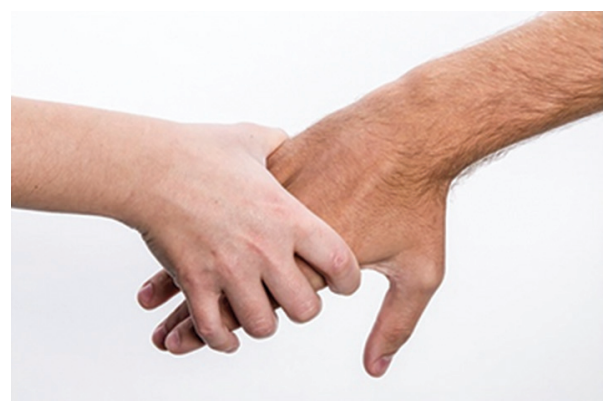

A practical way to easily assess the presence of inflammation at the MCP and MTP joint level is the Gaenslen Compression Maneuver ${ }^{3}$, which consists of applying lateral pressure to said joints, considering it positive in the case of presenting pain. This maneuver is of great utility nowadays with the increase in medical consultations through video calls since patients can be asked to perform it on themselves. Another maneuver that is of great importance is asking the patient to make a fist and make sure it is completely closed to assess the presence of inflammation in the hand indirectly.

As already mentioned, laboratory tests are mainly used to corroborate clinical suspicion and determine prognosis ${ }^{4}$. Tests that can be used include the determination of rheumatoid factor (RF) and anti-citrullinated cyclic antibodies (ACPA). The RF is positive in $60 \%$ to $70 \%$ of patients with RA, and if it is positive, it is not necessary to repeat it. High levels of this marker have been associated with greater joint destruction, but a negative result does not exclude the diagnosis ${ }^{5}$.
The presence of anti-CCP is more specific than RF for the diagnosis of the disease. It can be found years before it becomes apparent and associated with a more serious illness, but a negative result does not exclude the diagnosis. Erythrocyte sedimentation rate (ESR) and C-reactive protein (CRP) are two highly useful markers to estimate the level of disease activity, as they reflect the patient's state of inflammation.

Activity indices such as DAS28 are used to determine the state of the disease in patients and thus make better treatment decisions, which takes into account pain and inflammation in the joints that are most frequently affected by this group of patients, inflammation markers such as ESR and CRP, and the global assessment of the disease by the patient. The use of radiographs of the affected joints may be useful as a monitoring test to detect erosion but should not be ordered as an early diagnostic test ${ }^{6}$.

Key Points

- RA is a chronic inflammatory disease

- An early diagnosis, accompanied by correct treatment, prevents the progression of the disease

- The diagnosis of the disease is clinical

- Laboratory studies do not make the diagnosis, but they are useful in corroborating it

- Compression maneuvers and forming a fist are quick and easy ways to assess the patient.

\section{References}

1. Diagnostico y Tratamiento de Artritis Reumatoide en el Adulto. México: Secretaria de Salud; 2010.

2. Aletaha D, Neogi T, Silman AJ, Funovits J, Felson DT, Bingham CO $3^{\text {rd }}$ et al. 2010 rheumatoid arthritis classification criteria: an American college of rheumatology/European league against rheumatism collaborative initiative. Arthritis Rheum. 2010;62:2569-81.

3. Vega Morales D, Valerio JE, Elizondo MG. Do rheumatologists know how to squeeze? Evaluations of Gaenslen's maneuver. Rheumatol Int. 2015; 35:2037-40.

4. Mohan C, Assassi S. Biomarkers in rheumatic diseases: how can they facilitate diagnosis and assessment of disease activity? BMJ. 2015; 351:h5079.

5. Aho K, Palusuo T, Kurki P. Marker antibodies of rheumatoid arthritis: diagnostic and pathogenetic implications. Semin Arthritis Rheum. 1994; 23:379-87.

6. Colebatch AN, Edwards CJ, Østergaard M, van der Heijde D, Balint PV, D'Agostino MA, Forslind $\mathrm{K}$, et al. EULAR recommendations for the use of imaging of the joints in the clinical management of rheumatoid arthritis. Ann Rheum Dis. 2013;72:804-14. 